Organisations \$A1.5 million when costs are determined, it may well consider the experience to have been money well spent. It has received meticulous counsel from one of the nation's highest courts about what it might wish to say on the subject in the future. Equally, though, we would prefer to think that the Australian Federation of Consumer Organisations's experience will inspire other Davids of the tobacco control world to stone the lumbering Goliath of the tobacco industry with ever increasing legal and tactical accuracy.

We acknowledge the assistance in ensuring the legalistic accuracy of this paper provided by Neil Francey, barrister at law, who was the counsel appearing for the Australian Federation of Consumer Organisations before Justice Morling at the first instance and for the full Federal Court appeal
Copies of the appeal judgment are available for research purposes for $\$ A 20$ postage paid from Stephen Woodward at the address given.

1 Macaskill P, Pierce JP, Simpson JM, Lyle DM. Mass media-led antismoking campaign can remove the education gap in quitting behaviour. Am f Public Health 1992;82:96-8.

2 Department of Community Services and Health. Tobacco in Australia. A summary of related statistics. Canberra: Australian Government Publishing Service, 1990:12.

3 Chapman S, Woodward S. Australian court rules that passive smoking causes lung cancer, asthma attacks and respiratory disease. $B M \mathcal{F}$ 1991;302:943-5.

Doyle AE, Rand M, Powell LW, Simmonds W, Wing I, Zylstra W. The Australian Tobacco Research Foundation. Med f Aust 1988:148:152.

Chapman S. Tobacco industry health resch "blood money": the Brith .

Heath Pr. Tion Research Trul Com ril

Warner Ke. Tobacco industry scientific advisors: serving society or selling

7 Chapman S, Borland R, Hill D, Owen N, Woodward S. Why the tobacco industry fears the passive smoking issue. Int $f$ Health Services 1990;20

(Accepted 21 December 1992)

\title{
Alternative allergy and the General Medical Council
}

\author{
A B Kay
}

In July 1992 Dr Keith Mumby, a clinical ecologist, appeared before the professional conduct committee of the General Medical Council on five charges to do with his practice of clinical ecology. He was found guilty of two of the charges-touting for publicity and failing to give a patient adequate medical attention-and admonished. The GMC failed, however, to address the issue of the nature of Mumby's treatments-clinical ecology itself. This is based on the idea that some patients are unusually susceptible to their environment, the diagnosis and treatment are based on an unstandardised provocation-neutralisation test. A variety of medical bodies have failed to find scientific foundation for the technique. The GMC's policy on advertising services to patients is inconsistent, and in this case it has shown a regrettable reluctance to deal with the issue of treatments that are not scientifically validated.

In July 1992 the General Medical Council's professional conduct committee considered the case of $\mathrm{Dr}$ Keith Mumby, a clinical ecologist. The GMC called me as an expert witness. In the event my evidence-on the scientific value of clinical ecology - played little part in the proceedings because the charges brought by the GMC touched only peripherally on Dr Mumby's clinical activities. I describe the proceedings here, however, because they raise questions about the willingness of the GMC to protect patients from forms of diagnosis and treatments which have not been sufficiently validated and about its lenient attitude to a doctor who persistently touted for business by attracting the interest of tabloid journalists.

\section{The Mumby case}

Dr Keith Mumby graduated from Manchester University in 1971 . He did his preregistration year and a year of vocational training in general practice but then stopped working as a doctor until he opened an allergy clinic in 1982. Since then he has been featured in many newspaper articles. Highlights include "Allergy plight of nice-girl Nicky-'one sip of vodka turns me into a sex maniac" (News of the World magazine) and "Women could be turned on by a chunk of cheddar" (People).'

$\mathrm{He}$ had been arraigned before the GMC twice before, both times for canvassing. In 1982 he was found guilty of serious professional misconduct and undertook not to let it happen again. In 1987 he was found not guilty over a full page article in the Sunday Express. Dr Mumby has been the target of investigative journalism at least three times; the last of these, an article in Scotland on Sunday in $1991,{ }^{2}$ resulted in this year's GMC hearing.

On 13 July Dr Mumby appeared before the GMC's professional conduct committee charged:

(1) that he touted for patients using a publicity agent;

(2) that he caused avoidable distress by giving injections (as tests or treatment or both) in front of other patients and members of the public;

(3) that he gave the names of two patients to journalists without first seeking their permission;

(4) that he treated Ian Royan without taking a proper history or examination, or first contacting his general practitioner; and

(5) that he injected Royan with a substance he knew would harm him, in the presence of the press, and failed to given him adequate medical attention.

Dr Mumby was found guilty of only the first and last charges, for which he was admonished.

The evidence for charge 1 included a letter from Dr Mumby in August 1987 to his "publicity agent," freelance journalist Brian Whittle:

\section{Dear Brian,}

Herewith the letter from Mrs Massey. I think you will agree it's got the beginnings of a nice story. To re-emphasise, I would like this one played a little bit special if you can. Try to get it as a "Dr Mumby does it again", not just a patient story. The effect from the Sunday Express article is just beginning to wane slightly and a boost now would be absolutely terrific and see us right through to Christmas.

Dr Mumby said that the letter had been stolen and was therefore inadmissible, and that it was written in jest. Whittle agreed that it was a typical Mumby joke.

Dr Mumby successfully defended himself against causing distress by performing allergy tests in front of others and of giving patients' names to the press. Several witnesses, including other patients and $\mathrm{Dr}$ Mumby's staff, said that patients generally welcomed company during skin testing sessions, and all three expert witnesses (myself, Professor Anne Ferguson for the GMC, and Dr Jonathan Brostoff for the defence) 


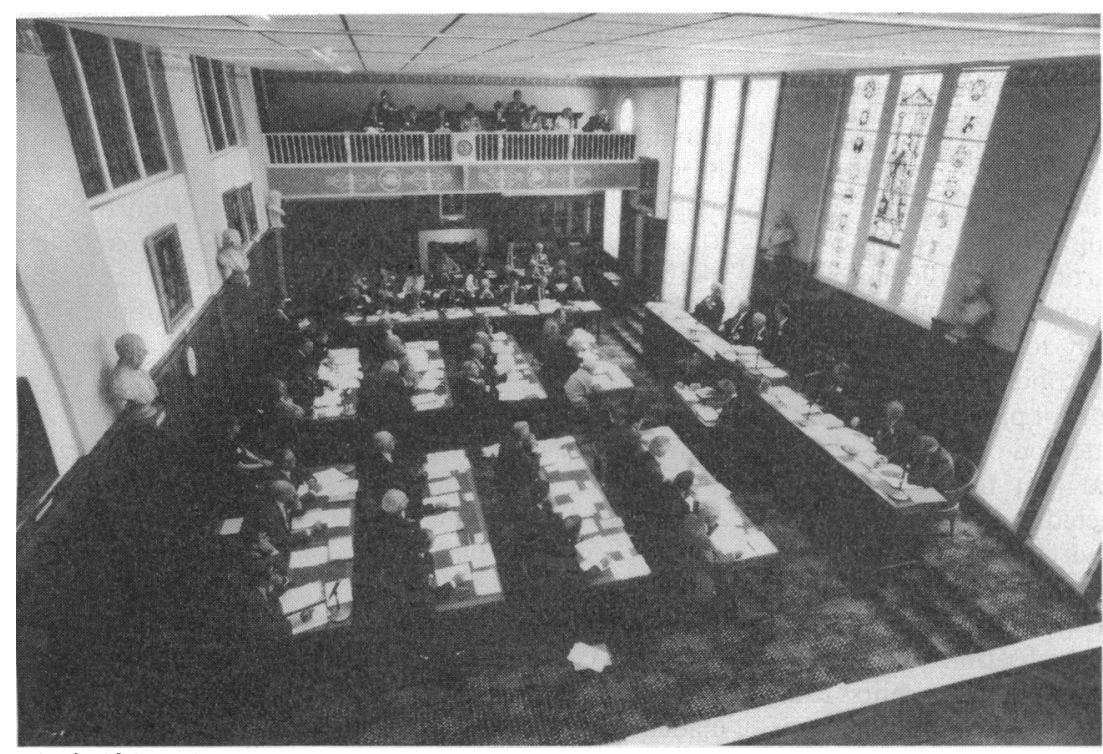

The GMC in session said that privacy was necessary only in special circumstances.

Dr Mumby, supported by his staff, said that he always asked patients' permission before giving their names to journalists. They all made it clear that handing patients over to the press was a regular occurrence (a point that none of the committee commented on or asked questions about). One of the patients named in charge 3, Ian Royan, said he had never authorised Dr Mumby to give his name to any journalist but was telephoned by Archie Mackay of the Sunday Mail and agreed to rendezvous with him at Dr Mumby's next clinic. These clinics were held irregularly on Sundays in rooms hired at the Copthorn Hotel, Glasgow. He had not objected to being photographed but was upset to see photographs of himself and a feature in the Sunday Mail of 4 October 1990 headed "The sheer agony of a food allergy."

Dr Mumby said he had a duty to put the potential benefits of allergy diagnosis and treatment in public view, which was why he attracted publicity in newspapers rather than professional journals. He had organised the Sunday Mail article to repudiate "an awful paper in the New England fournal of Medicine" (see below).

\section{Dr Mumby's techniques}

In answer to charge 4 that he had treated Royan without taking a proper history or examination or consulting his general practitioner, Dr Mumby said he took the clinical history in the form of a questionnaire which patients filled out in advance but he rarely examined patients because they had usually been examined many times elsewhere and because taking a history by questionnaire was an established technique of clinical ecology. Dr Brostoff concurred. Professor Ferguson and I said that a routine clinical history and examination (preferably in private) were essential in helping to establish the correct diagnosis and treatment of all patients, particularly in people who might be under the mistaken impression that their symptoms were due to allergy. Professor Ferguson also emphasised the existence of serious functional symptoms which could be reinforced by suggestion in a susceptible individual.

Dr Mumby said, "It would be a waste of time taking Mr Royan's blood pressure or listening to his chest. You can see he's a very strange man... if he twitches after eating meat pies and he stops eating meat pies and stops twitching it doesn't matter if it's psychological or not."
Dr Mumby practises the Miller technique, ${ }^{4}$ the standard method of clinical ecologists. $\mathrm{He}$ has seen about 6000 patients over the years and all except six had suffered from allergies. Patients were tested for allergy with a wide variety of substances, including gas and petrol fumes, milk, coffee, yeast, soya, and onion.

Most patients reacted to injections of a number of substances and he made them up custom made "vaccines" of supposed antidotes. When they got symptoms they were to place a couple of drops under the tongue. Patients were regularly retested (at a cost of $£ 140$ upwards) and their allergies were found to shift around capriciously so their vaccines had to be changed.

In evidence I said that allergen extracts should be standardised and prepared according to good manufacturing practice and that it was absurd to inject patients with extracts of gas and petrol fumes. These cause irritant reactions but were not allergens. Many substances, particularly food extracts, often give false positive reactions in allergy skin testing. Conventional allergists use skin tests to confirm the diagnosis, not to make it. I also expressed concern about the possibility, albeit rare, of producing generalised anaphylaxis in certain sensitised patients who are tested by intradermal injections rather than the "skin prick" method. For this reason I believed that Dr Mumby should always have had full resuscitative equipment readily at hand. In reply Dr Mumby said that he had an oxygen cylinder and mask in his kit but no electrocardiogram or defibrillator. "I don't carry a defibrillator because what I do isn't dangerous, like conventional allergy tests."

Charge 5 in fact addressed the potential harm of the substances used by clinical ecologists. It alleged that Dr Mumby had injected Royan with substances that might harm him and failed to given adequate medical attention. He had injected Royan with various substances in the hired suite at the Copthorn Hotel, Glasgow, and videotaped the session. The video recording showed Royan going into spasms and gradually tipping over until he gently slid off his chair. At this stage Dr Mumby gave him drops of dilutions of the substance into his mouth until he became his normal self again. Dr Mumby said he told Royan, "Pull yourself together-the act's over." He disputed that Royan was at risk: he had given him the correct treatment and calm reassurance-which was the essence of his treatment. Royan, who was unemployed owing to his health problems, paid $£ 800$ to Dr Mumby altogether.

\section{Issues arising from the case}

CLINICAL ECOLOGY

The clinical ecology movement, founded in the 1950s by the American allergist, Dr Theron Randolf, is based on the belief that certain people are unusually susceptible to the adverse effects of their environment; this results in a disease which clinical ecologists call "environmental illness" but which has several names, including "total allergy syndrome," "twentieth century disease," and "food and chemical sensitivities." Environmental chemicals and foods are said to be responsible for an unlimited variety of symptoms which occur in the absence of physical findings or abnormal laboratory results.

Although the idea that the environment is responsible for a multitude of human health problems is appealing, the basic concepts of clinical ecology are unproved. Clinical ecologists therefore attempt to diagnose and treat a disease which conventional doctors believe does not exist.

Provocation-neutralisation testing is performed in several different ways without any standardisation. Some practitioners, including Dr Mumby, give sub- 
cutaneous injections in a completely unblinded fashion and record the symptoms that ensue. Others administer substances by intradermal injections and record the size of the cutaneous weal. Either lower or higher doses are then injected serially until the weal or the symptoms disappear. The last of these is then regarded as the "neutralising dose" and is then used for treatment (usually in the form of sublingual drops). In the New England fournal of Medicine article which incensed $\mathrm{Dr}$ Mumby the validity of provocation of symptoms by intracutaneous tests to identify food sensitivities was evaluated under double blind conditions. ${ }^{3}$ The protocol was accepted by proponents of provocation testing, and clinicians who used this method participated in the study. The article concluded that the frequency of positive responses to the injected extracts appeared to be the result of suggestion and chance and hence the method was not scientifically valid. The United States Department of Health and Human Services specifically excludes provocation-neutralisation and similar forms of food allergy testing and treatments from reimbursement under Medicare. ${ }^{5}$ Reimbursement is also not allowed under British private health schemes - except (bizarrely) when it is requested by a doctor who is, or has been, an NHS consultant.

There have been many severe criticisms of the techniques of clinical ecology, ${ }^{6-9}$ all concluding that the concept of "environmental illness" is unfounded and that the claims of clinical ecologists are invalid because they do not properly control their studies or define objective parameters of illness. Indeed the Royal College of Physicians stated, "The public should be warned against [all] methods of diagnosis and treatment which have not been validated".

\section{ADVERTISING}

Not surprisingly, Dr Mumby's sentence was greeted with exasperation by the quality press, particularly in the areas where Dr Mumby practises. The New Statesman Society was concerned about the "relative leniency of the GMC's disciplinary action." And Scotland on Sunday said, "The GMC is unsure of its ground when dealing with practitioners of alternative forms of medicine. It shows that unproven fringe techniques can be used on the public with little policing from the body with a remit to protect patients from rogue doctors. ${ }^{11}$

The GMC may have to rethink its policy on advertising. On the one hand, the public and the profession surely cannot accept leniency when a doctor indulges in indiscriminate showbiz type advertisement. On the other hand, there are proved services available but no mechanism by which the public can be readily informed about them. The unsatisfactory policy of the GMC on advertising is further illustrated by the fact that general practitioners can include conventional allergy desensitisation as part of the services they advertise but an NHS hospital with consultants trained in allergic diseases cannot. Yet the 1986 CSM Update on desensitising vaccines arose from concern about 26 deaths from anaphylaxis since 1957, five in the previous 18 months. ${ }^{12}$ Virtually all the deaths occurred in general practitioners' surgeries. ${ }^{13}$

\section{The GMC's case}

At the beginning of the hearing the committee chairman, Sir Herbert Duthie, said that it was not a trial of alternative medicine or of the provocationneutralisation test. In fact this put severe restrictions on the committee's deliberations, and the chairman repeatedly had to advise counsel for both the GMC and the defence that it was not their function to comment on the relative merits or otherwise of alternative forms of medicine. Why this reluctance to tackle the issue of the worth of this particular form of treatment?

A previous High Court judgment in the United Kingdom in 1991 (Lorraine Taylor $v$ Airport Transport and Warehouse Services Ltd) had ruled that the methods of a clinical ecologist (Dr Jean Monro) were "in many cases bizarre and unscientific ... and her methods and treatment have no parallel or place in the NHS routines." 14 That court had, in fact, subpoenaed a draft copy of the Royal College of Physicians' report on allergy. ${ }^{9}$ So it would have been possible for the GMC to try to challenge the basis of clinical ecology.

Moreover, the GMC has in the past challenged unorthodox treatments. For example, in 1989 it charged Dr James Sharp over his adoptive immunotherapy treatment with "advising and treating patients with AIDS, AIDS related complex and HIV infection without sufficient knowledge, training or experience to treat the conditions competently" and "offering the treatment without proper clinical trials ... and despite inadequate independent scientific evidence to support it."

One can only speculate that the GMC took the easy option and avoided testing the issue of clinical ecology head on because it feared a lengthy presentation of evidence on both sides, with the risk of an inconclusive result.

\section{What should the GMC do?}

The GMC must face the issue of alternative allergy practice, particularly when a diagnosis is given of an illness which conventional doctors believe does not exist and when potentially dangerous dubious substances are injected. Clinical ecology is one of the more controversial forms of alternative medicine. It has a cult-like following with the potential to exploit gullible people and reinforce obsessional behaviour. The GMC should consider censoring all forms of diagnosis and treatment which, by reasonable standards, have consistently failed to show clinical efficacy. There should be a close dialogue between the GMC and the royal colleges to ensure that procedures which are potentially harmful have been validated by careful placebo controlled clinical trials using generally accepted procedures.

The GMC should also reconsider its views on advertising. It needs to be much more severe with outrageous advertisements but, equally, it should not obstruct the public's access to proved specialist services.

1 Cited in: Wood B. Keep taking the tabloids. New Statesman Society 1992; 31 July: $14-5$

2 Watson J. Miracle allergy cure exposed as sham. Scotland on Sunday 1991.

3 Jewett DL, Fein G, Greenberg MH. A double-blind study of symptom provocation to determine food sensitivity. N Engl F Med 1990;323:429-33.

4 Miller JB. Food allergy: provocative testing and injection therapy. Springfield, Illinois: Charles C Thomas, 1972:7.

5 Health Care Financing Administration. Medicare program. Exclusion from medicare coverage of certain food allergy tests and treatments. Federal medicare coverage of certain food
Regulations 1983;48(162);37716-22.

6 American Academy of Allergy and Immunology. Position statements-clinical American Academy of Allergy and Immunology. Pos
ecology. $₹$ Allergy Clin Immunol 1986;78:269-70.

7 California Medical Association Scientific Board Task Force on Clinical Ecology. Clinical ecology-a critical appraisal. West f Med 1986;144: 239-45.

8 American College of Physicians. Position paper: Clinical ecology. Ann Intern Med 1989;111:168-78.

9 Royal College of Physicians Committee on Clinical Immunology and Allergy. Allergy. Conventional and alternative concepts. London: RCP 1992.

10 Wood B. Keep taking the tabloids. New Statesman Society 1992;31 July:14-5.

11 Policing the doctors. Scotland on Sunday 1992;19 July:13.

12 Committee on Safety of Medicines. CSM update: desensitising vaccines. $B M O$ 1986;293:948.

13 Rawlins MD, Wood SM, Mann RD. Hazards with desensitising vaccines. In Kurth R, Kroon A, Schaeffer, Siefert, Sisk C, eds. Regulatory control and Kurth R, Kroon A, Schaeffer, Siefert, Sisk C, eds. Regulatory control and
standardization of allergenic extracts. Stuttgart: Gustav Fischer, 1988:147-51. 14 Lorraine Taylor $v$ Airport Transport and Warehouse Services Ltd. 90/NJ/5076, 1991. 